\title{
CAUSES OF DETERIORATION OF OTTOMAN MOSQUES
}

\author{
MARIA LOUKMA \& MARIA STEFANIDOU \\ Laboratory of Building Materials, School of Civil Engineering, Aristotle University of Thessaloniki, Greece
}

\begin{abstract}
The existence of few Ottoman mosques out of the many existing a few decades ago in the region of Macedonia, northern Greece, makes them an important piece of historic and cultural heritage and strengthens the need to preserve them. This paper focuses on mapping the pathology of five mosques with similar typological characteristics, in relation to their environment, building materials and the different uses that these structures served through history. The current situation of these monuments is the result of the effect of aging, the environmental and human interventions. As a result of these factors, the monuments present structural problems of geometric form, i.e. loss of material and movements and also mechanical problems as cracks, coating loss, disintegration. The main causes of these damages are the abandonment and the aging of construction materials, as well as the lack of systematic maintenance. The biological factor, the humidity coming from the roof which, in most cases has been destroyed, or rising from the ground, are important factors for disintegration.
\end{abstract}

Keywords: Ottoman mosques, pathology, restoration of monuments, causes of deterioration.

\section{INTRODUCTION}

Mosques, as religious buildings of the Ottoman Empire, were built and maintained by the Muslim residents, from the 14th to the early 20th century [1]. By the time they ceased to function as religious spaces, they were converted, abandoned and destroyed to take different uses. In most cases, the area once used for prayer by the Muslims, converted with the necessary each time interventions to storage, workshops or residences with new partitions. Nevertheless, their robust structure prevails in the urban environment of many cities. In recent decades many of them, although characterized as listed historical monuments, were abandoned and the community has not concerned about their restoration. They belong to the Ministry of Culture which is responsible for their preservation state.

This paper examines the pathology of five mosques in the region of Macedonia, Greece to assess their conservation status and to evaluate their need for restoration. The recording of their preservation status combined with the environment of the monument, the way and the building materials and procedures create a framework for understanding the factors and mechanisms of deterioration for each build.

The mapping of the pathology of each monument took place with on-site observation, photographic documentation, design drawings and historical research.

\section{THE FIVE OTTOMAN MOSQUES: RECORDING THEIR DETERIORATION}

The mosques that were studied (Fig. 1) are the Koursoum Mosque, the last surviving mosque in the city of Kastoria, Orta Mosque, one of the two mosques exist in the city of Veria, the Geni Mosque in the city of Edessa, the Ahmet Bey Mosque in Giannitsa that is saved in semi ruined state and the mosque that is located in the village of Exochi Drama, on the GreekBulgarian borders.

These mosques constitute a group according to the typological characteristics and size. They are single domed buildings with almost square floor plan of external dimensions approx. $10 \times 10 \mathrm{~m}$, besides the Geni Mosque which is $14.70 \mathrm{~m}$. Originally, in all of them there was a portico but today only in the Geni Mosque survives, while on the rest the degree of preservation varies from parts to traces of facade of the building (Koursoum Mosque). The 


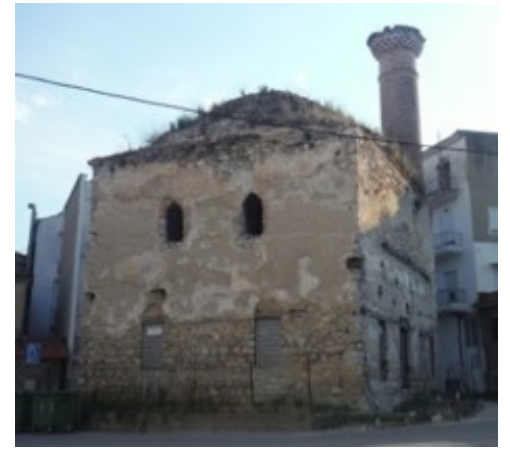

(a)

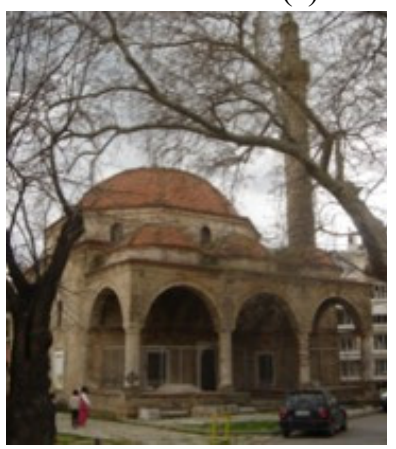

(c)

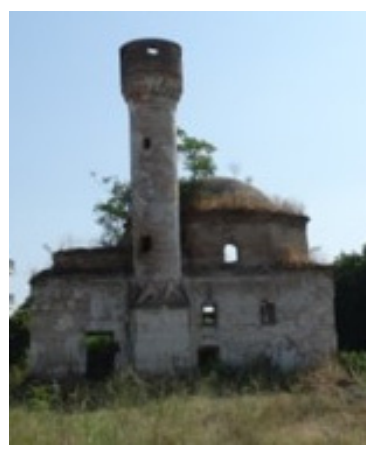

(d)

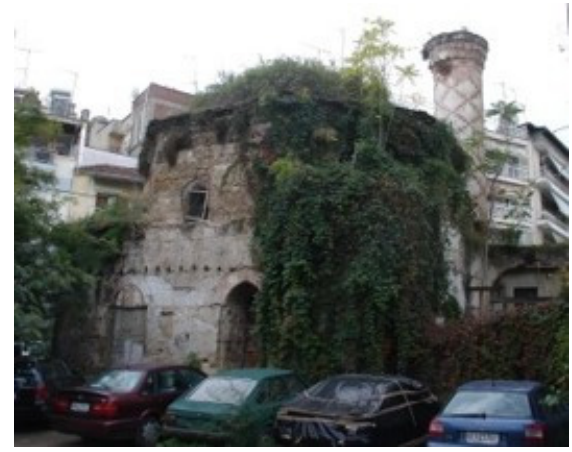

(b)

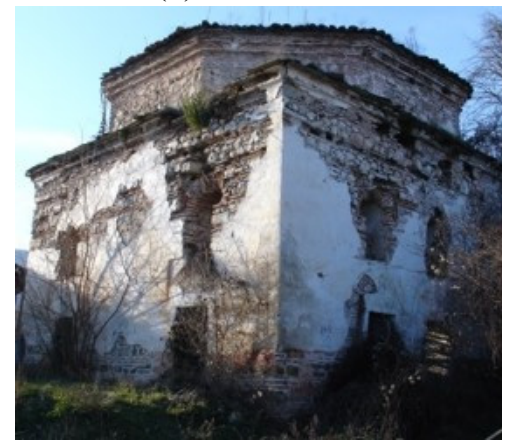

(e)

Figure 1: The five mosques. (a) Koursoum Mosque; (b) Orta Mosque; (c) Geni Mosque; (d) Ahmet Bey Mosque; and (e) Mosque in Exochi.

minaret that existed in all the cases, survives as a piece that protrudes from the bulk of the building until the height of the balcony, except in the case of the mosque in the Exochi Drama where there are only traces of it in the side of the building.

The materials used for the construction of mosques are stones, mortar and bricks with similar building techniques. The perimeter walls are made with row or semi curved stones, placing intermediate bricks in rows and structural mortar. The Orta Mosque and the Geni Mosque differ in which similar rectangular carved stones are used for the construction of the walls. In all cases, the openings and the dome are constructed with bricks and mortar.

\subsection{The Koursoum Mosque of Kastoria}

In the centre of Kastoria is the only surviving Ottoman mosque of those constructed during the Ottoman period. This is a single-domed building, external dimensions $10.70 \times 10.70 \mathrm{~m}$, with rectangular protrusion on the shape of a minaret which is preserved up to the balcony. It is constructed of masonry with semi curved stones and bricks while the dome and the openings were built only by bricks.

The Koursoum Mosque is now preserved in relatively good condition. By the time it stopped being a religious place, received various uses while in recent decades remains closed. The different uses that received as well as the abandonment of the building, resulted on the loss of its inside mobile constructions although there are traces of them on walls and openings 
(window frames, metal railing) (Fig. 2(a)). There are no sufficient elements for the flooring material and the way the building's foundation were made. The plaster is saved in moderate condition where there are areas both externally and internally in the building, keeping only a small percentage of its colour decoration [2].

The building presents problems of deterioration from moisture and vegetation growth. The main problem lies in the roofing of the building where the external tile loss of the dome and the internal generated cracks, combined with the collapse of parts of the octagonal drum lower the mechanical resistance and make the construction more vulnerable to deterioration agents. In these places becomes easier the penetration of rainwater, favouring the development of vegetation, resulting in degradation of building materials (Fig. 2(b)).

On the walls recorded small cracks, vegetation into the joints and loss of wood joins, while in northwest masonry problems are more extensive (Fig. 2(c)). Cracks were detected at the minaret, both on the northwest side, and in contact with the bulk of the building.

\subsection{Orta Mosque of Veria}

In the city of Veria two mosques are preserved: the Medresse Mosque, which has been restored and is used as a venue and the Orta Mosque, which remains closed.

The Orta Mosque is a single-domed building, external dimensions of $10.32 \times 10.15 \mathrm{~m}$. with rectangular protrusion on the shape of a minaret that survives up to the balcony and part of the portico. The mosque is constructed of curved rectangular stones and mortar while the dome and the configuration of openings are made with bricks and mortar.

The mosque was built after the conquest of Veria (1433), in 1490/1491 in accordance with the relevant inscription [3]. After 1912, the mosque received various uses while since 1980 functioned as storage of antiquities [4]. The main interventions that were made were the removal of mobile structures, the closing of openings with bricks, and the coating of the floor with cement mortar.

Today, the building is in poor condition with damages to the structure. Main causes of deterioration of the monument is the extensive vegetation, up to trees that have grown and the loss of tiles at the dome that led to wide cracks (Fig. 3(a)). In addition, the presence of a tree trunk in southern corner of stonemasonry has resulted in the disruption of the structure and increased the stress of the whole building (Fig. 3(b)). At the interior, loss of coating, weathering of building mortar and disruption of construction mainly in areas that come in contact with the floor are recorded.

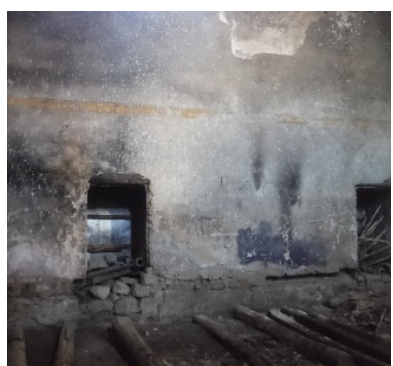

(a)

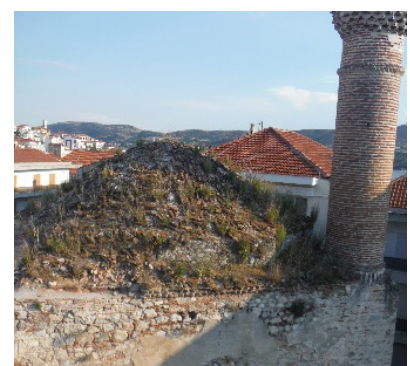

(b)

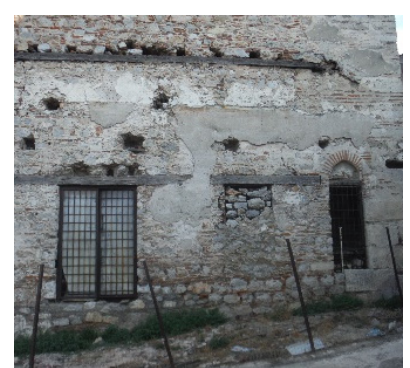

(c)

Figure 2: Koursoum Mosque. (a) Interior view; (b) The roof of the mosque; (c) Northwest side view. 


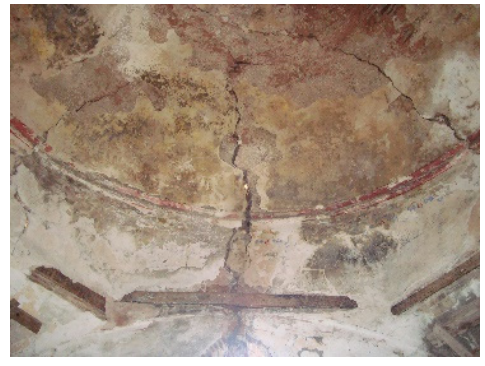

(a)

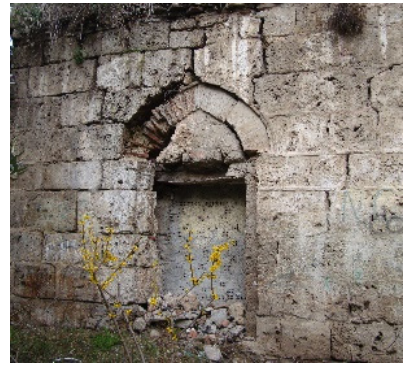

(b)

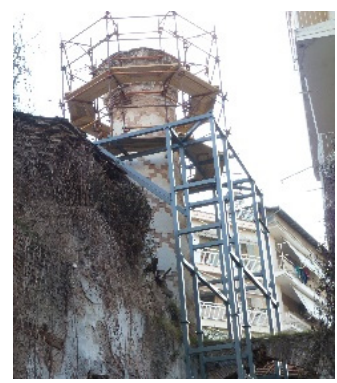

(c)

Figure 3: Orta Mosque. (a) Cracks in the interior; (b) Disruption of the structure; (c) Scaffold around the minaret.

Around the 1980 s, as a temporary measure to protect the monument an internal wooden scaffold was placed in the four corners of the building, while the summer of 2017 a metal scaffold was placed around the minaret due to deviation from the vertical (Fig. 3(c)).

\subsection{Geni Mosque in Edessa}

The Ottoman presence in the city of Edessa gave several monuments which erected to support the Islamic way of life. Today, very few have survived including the Geni Mosque, located at the boundary of the old Turkish quarter in the South-West of the city.

The monument consists of a single prayer space, external dimensions of $14.80 \times 14.70 \mathrm{~m}$. covered by a hemispherical dome, the minaret is built in a protrusion and in the north side exists a portico with columns. The mosque is built with curved stones where at the exterior follows the isodomic construction system and at the interior was coated by plaster, while the dome is solely from bricks.

The Geni Mosque appears to have suffered extensive repairs since construction. Externally, the intervention on a large scale into the joints of the walls with cement mortar, blocking some of the openings, the scaly tiles in domes and inner coating of the floor with cement are the main interventions that are observed.

The building after the 1924 became a public property and mainly used as storage space and as archaeological museum from 1942 to 1944. Today the monument is closed and is used as a storage area by Ephorate of Antiquities [5].

It is kept in relatively good condition, facing problems mainly because of moisture and vegetation. At the interior, the intense presence of moisture leads to detachment of coatings and the weathering of building materials (Fig. 4(a)). The presence of moisture and the growth of the biological agent is continuous and is deteriorating due to the loss and detachment of the roof tiles (Fig. 4(b)). The main problem occurs at the attachment point of the wall with the north-east domes of the portico. In the context of openings, in pendentives and in the drum of the dome some cracking appears. In the portico, due to water penetration, detachment of mortar and bricks is observed at the domes (Fig. 4(c)). Finally, the interventions made with cement over a large area, altering the form of construction and create additional problems of alteration of building materials. 


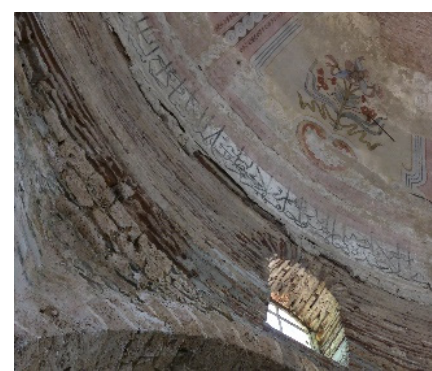

(a)

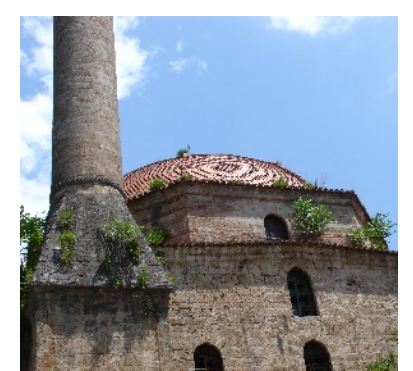

(b)

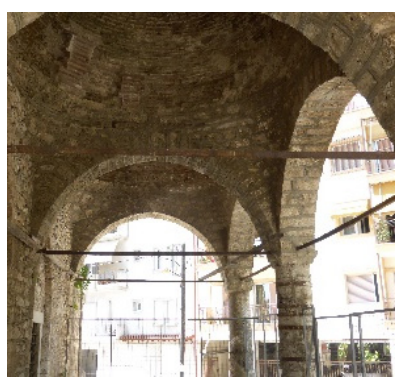

(c)

Figure 4: Geni Mosque. (a) Detail of the interior; (b) Part of the exterior front view; (c) Part of the portico.

\subsection{Ahmet Bey Mosque in Giannitsa}

The town of Giannitsa was founded in $1383 / 85$ by Gazi Evrenos, commander of Sultan Murad A' and evolved into an important city with intellectual and artistic activity. Among the charity institutions founded by the descendants of Gazi Evrenos there was the mosque of Ahmed Bey. Its construction is placed in the second half of the 15th century [6]. It is located at the western boundary of the city, inside the abandoned military camp "Kapsali".

The monument is preserved in a bad state of preservation. This is a small domed mosque that consists of the prayer space, measuring $9.25 \times 9.40 \mathrm{~m}$, the minaret and a part of the portico. It is made of masonry structure where rows of stones surrounded by bricks and follow three or four rows of bricks.

The building received interventions and modifications over the years. During its operation as a mosque, the key changes identified are changing the entry to the prayer room and the closure of the portico. During the last phase of operation as a mosque, in the 19th century and until 1912, it lies in the ottoman military camp and the external and internal sides are covered of plaster which alter its form. When the monument becomes part of the Greek military camp the changes are irreversible. The endpoint of the minaret was demolished and a brick oven is built in the portico. In the period 1967-1973 an explosion resulted in the loss of north-east part of the mosque [6].

Today, the monument faces severe problems of deterioration due to the loss of structural material (Fig. 5(a)). The destruction of north-east side, part of the two in touch walls and large section of portico (Fig. 5(b)) resulted in the disruption of the masonry structure and increase the probability of a total collapse. Cracks on walls and peeling of mortar (Fig. 5(c)) in combination with environmental conditions and vegetation make the monument's preservation even worse.

\subsection{Mosque in Exochi of Drama}

In Exochi village, $50 \mathrm{~km}$ NW of Dramas in the Greek Bulgarian border, an Ottoman mosque is preserved. During the Ottoman period, the village was inhabited of Muslim residences [7].

The monument consists of a single prayer space, external dimensions $10.23 \times 10.30 \mathrm{~m}$., covered by a hemispherical dome, in northern side part of the portico is saved while only the 


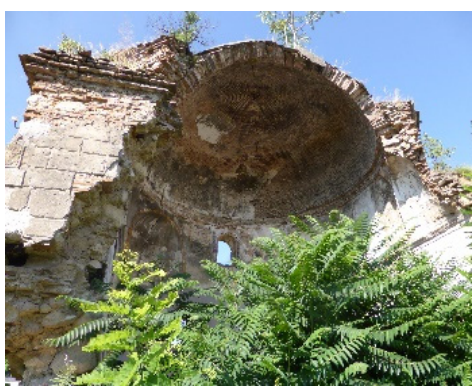

(a)

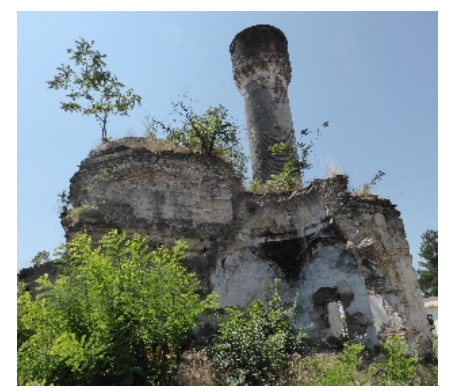

(b)

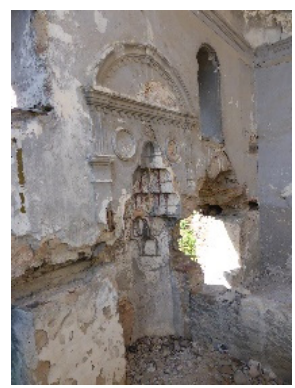

(c)

Figure 5: Ahmet Bey Mosque. (a) The loss of the structure; (b) View of the portico; (c) Detail of the interior.

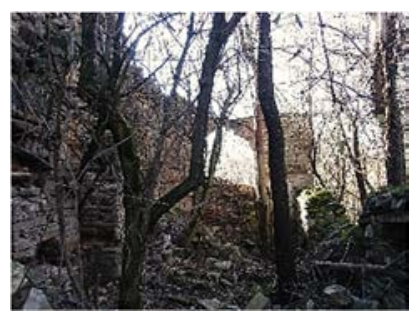

(a)

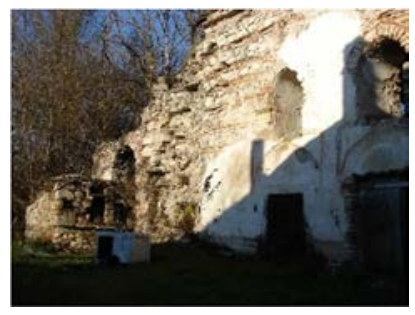

(b)

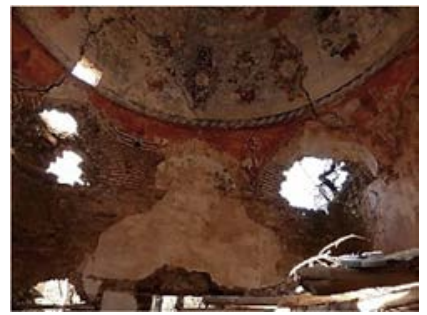

(c)

Figure 6: Mosque in Exochi. (a) The position of the portico; (b) The position of the minaret; (c) Detail of the interior.

position of the minaret is recognized. The mosque is constructed of masonry with rows of stones and two or three rows of bricks.

The mosque has not undergone extensive repairs from its construction until today. During its function as a mosque renovation probably took place with the addition of plaster coating both inside and outside. By the time they ceased to function as a mosque, was used for animal housing and warehouse by closing of the openings and conversion to doors of some windows.

The building faces problems of pathology that have disrupted the masonry structure due to the loss of the portico (Fig. 6(a)), the destruction part of north sided prayer space and part of the external corner of the particular space in the joint with the portico and the minaret (Fig. 6(b)). Material loss and cracking is also recorded, in two northern pendentives in the dome (Fig. 6(c)), drum and smaller on the walls. At the interior of the building painting decoration is preserved to a satisfactory degree and externally plaster is preserved in many surfaces. The inflow of water into the interior of the monument due to loss of material combined with the environmental conditions and vegetation accelerate the weakening of construction and alteration of building materials.

\section{CONCLUSIONS}

In this study, a pathology examination of five Ottoman mosques that are preserved in the area of Macedonia they showed that face various problems.

These are buildings located in an urban environment, almost square floor plan, constructed of masonry with the use of local stones, compact bricks and strong mortar. These monuments 
are robust and austere structures. The high quality materials combined with the construction technology of that era contribute better to the durability of the whole structure.

The pathology of each monument differs and depends to a certain extent by the microclimate is created and the uses that the building served. The ageing of building materials and the long-term lack of maintenance contribute to their relevant low preservation state. The study showed that in the monuments, the humidity and the biological factor, impact negatively and increase the problems.

In particular, the Koursoum Mosque in Kastoria and the Geni Mosque in Edessa are those that are kept in relatively good preservation condition. Their form is not altered even though they received successive uses in the past. The problems come mainly from moisture and vegetation through the roof. The result is the deterioration of building materials (mainly of bricks and mortar) and the detachment of the interior plaster coatings.

The Orta Mosque in Veria is facing serious structural problems mainly of mechanical nature. The interior cracks and the partial degradation of masonry accelerate its deterioration. The intense vegetation has played a key role on its low preservation status.

Pathology problems faces also the mosque in the Exochi Drama. The collapse of the portico and the loss of the minaret caused the collapse of part of the facade. This resulted in the disruption of the masonry structure of the building and the continuing alteration of building materials.

Alarming is the situation of Ahmed Bey Mosque in Giannitsa, which is very possible to collapse due to the loss of almost half of the building construction.

Regarding the treatment of their preservation status, the main principle of the interventions is the aesthetic and morphological recovery of each monument so as to be part of the contemporary society and receiving modern uses. As for the technical part, the basic principle is the use of compatible interventions with authentic materials of construction of the building.

Preserving the cultural remnants constitute an act of civilization according to the principles of International Declarations and Charts [8]. North Greece is especially rich in monuments and buildings from the Byzantine and the Ottoman period.

For the proper implementation of interventions, primary element is the structural study of each monument. The problematic structural condition of the Ottoman mosques enforces a structural study which will determine and schedule the order of their required interventions. From the monuments which were studied, the Ahmet Bey Mosque in Giannitsa is in worse condition and follow the mosque in Exochi of Drama and the Orta Mosque of Veria.

As far as the interventions of the five mosques are concerned, they could be grouped as follows:

1. Temporary structure reinforcement. In cases that the preservation status of the loadbearing structure has been corrupted, is considered to place temporary structure reinforcement before any restoration work. From the monuments which were studied, three of them (Ahmet Bey Mosque, mosque in Exochi of Drama, Orta Mosque) should be temporary reinforced as a whole, while for the other two mosques temporary support may be limited to the dome.

2. Removal of later additions and modern incompatible materials. Specifically, removal of modern materials of the monuments (from openings that have been construct) and removing sediment deposits that have covered floors and parts of buildings.

3. Excavation investigation. After the removal of all additions and interventions excavation sections are necessary to be carried out both inside and on the perimeter of each Monument for revelation of their foundation method. The aim of the excavation 
investigation is to record items that are not preserved, but their traces may be present, such as the level and type of flooring, the foundation method and the boundaries so as to determine the shape of the monument.

4. Removal of plants and trees. The vegetation that has developed has devastating consequences on the walls and particularly in domes.

With the completion of the above tasks there will be a full understanding of each monument and will be redefining the proposed rehabilitation interventions.

\section{REFERENCES}

[1] Choulia, S., The religious Ottoman buildings in Greece. Ottoman Architecture in Greece, E. Mproyskari (ed.), Ministry of Culture Directorate of Byzantine and PostByzantine Antiquities, pp. 45-50, 2008 (in Greek).

[2] Loukma, M., Siafaka, A., Birbili, E., Tantsis, A. \& Stefanidou, M., Koursoum Mosque: the last ottoman mosque in Kastoria, The archaeological work in Macedonia and Thrace, 30th meeting, March 2017 (Proceedings will be published in Greek).

[3] Tsilipakou, A., Orta Mosque \& Mproyskari, E. (ed.), Ottoman Architecture in Greece, Ministry of Culture, Directorate of Byzantine and Post-Byzantine Antiquities, p. 297, 2008 (in Greek).

[4] Mavromatidou, V. \& Tsilipakou, A., Proposal for the restoration and re-use of the Orta Mosque in Veria, Proceedings of the Scientific Meeting Historical Islamic Mosques, Ministry of Culture, Directorate of Restoration, Service of Modern Monuments and Technical Works, pp. 15-30, 2013.

[5] Matskani, A., Study of Maintenance-Restoration-Reuse of the Geni Mosque in Edessa, MSc thesis, 2008 (in Greek).

[6] Argirakis, D., Xalkidi, A., Skiadaresis, G., Ignatakis, Ch., Karadedos, G. \& Stefanidou, A., The mosque of Ahmed Bey in Giannitsa: restoration study and structural aid. The archaeological project in Macedonia and in Thrace, 23, 2009, Ministry of Culture \& Aristotle University of Thessaloniki, pp. 183-194, 2013 (in Greek).

[7] Messis, V., Ottoman mosque in the Exochi of Drama and the mosque of Karatza Pasha in GkotseNteltsef Bulgaria. Diode, Bi-annual Periodical Publication Speech Art Drama, 8(1), pp. 68-91, 2015 (in Greek).

[8] The Venice Charter, 1964 and The Nara Document on Authenticity, 1994. 